\title{
SITUAÇÃO EXISTENCIAL DO IDOSO DE CLASSE MÉDIA*
}

\author{
Ivalina Porto**
}

\section{Resumo}

O artigo faz uma reflexão sobre os dados coletados na pesquisa que analisou os aspectos biopsicossociais do idoso de classe média. A análise de conteúdo das respostas da entrevista permitiu inferir como vivem os idosos sujeitos do estudo e propor ações com vistas a uma mudança de atitudes, valores familiares e sociais com respeito à velhice.

Palavras-chave: Idoso. Classe Social. Situação Existencial. Aconselhamento.

\section{Classe Social e o Idoso}

Como este trabalho teve por objetivo verificar a situação existencial de um grupo de idosos de classe média, faz-se necessário, inicialmente, traçar algumas considerações sobre classes sociais. A organização da sociedade, dividida em classes sociais, é feita de tal maneira que os elementos econômicos aparecem unidos aos elementos políticos, religiosos e sociais. Santos confirma essa afirmativa dizendo que "[ . . . ] por classes sociais se entenderão os agregados básicos de indivíduos numa sociedade, os quais se opõem entre si pelo papel que desempenham no processo produtivo, do ponto de vista das relações que estabelecem entre si, na organização do trabalho e quanto à propriedade" (1983,p. 41). A classe média surge nas sociedades capitalistas atuais como resultado do aburguesamento cada vez maior da classe operária e da desclassificação de uma parte cada vez maior da burguesia. Os traços fundamentais que caracterizam classe média em nosso sistema social, conforme Galache e André (1992), considerando o nível econômico, são os burocratas intermediários entre classes populares e os donos do poder ou da

\footnotetext{
* Este trabalho é parte da Dissertação de Mestrado da autora, realizado na Pontifícia Universidade Católica do Rio Grande do Sul - PUCRS.

** Professora de Psicologia do Departamento de Educação e Ciências do Comportamento da Fundação Universidade Federal de Rio Grande (FURG). Doutora em Psicologia - Universidade de São Paulo (USP). Gerontóloga pela Sociedade Brasileira de Geriatria e Gerontologia (SBGG).E-mail: ivalina@terra.com.br
} 
empresa; socialmente trata-se de grupos de integração, justamente pelas posições na rede organizacional da sociedade; culturalmente, os componentes da classe média comungam com os valores das classes superiores, alimentam um moralismo herdado e fruto da educação, são difusores desses valores justamente por sua posição no campo da educação e comunicação; politicamente, pode-se contar, no dia-a-dia, com o conservadorismo da classe média, mas, nos momentos de crise, intelectuais e técnicos interiorizam as crises sociais e as exprimem de maneiras radicalizadas. Poulantzas (1978), ao falar sobre classe média, a classifica como o baluarte mediador e o fator fundamental de equilíbrio entre a burguesia e a classe operária. Não somente a classe média é assim considerada por ele, como, também, a vemos como o eixo central dos processos sociais. É na classe média que certamente se encontra o equilíbrio cultural da sociedade, haja vista que aí se aglutinam os elementos mantenedores da economia do país em termos de mão-de-obra especializada e tecnicista. Embora não se constituindo na maioria da população, é a mais significativa, onde se podem buscar subsídios para analisar a família e a sociedade, já que dela emanam os caracteres responsáveis pela moral e os costumes. $\mathrm{O}$ enfoque dado ao idoso de classe média, neste trabalho, deve-se justamente a importância atribuída a esses sujeitos como responsáveis pela moral, costumes, cultura e manutenção dos princípios sociais. Nesta pesquisa serão considerados como pertencentes à classe média os idosos que por seu nível cultural, recursos econômicos, status social e formação profissional, se enquadram ao conceito amplamente difundido que se tem de classe média na sociedade atual. No item a seguir, descreve-se o método, delineamento, objetivos, participantes, instrumento da pesquisa e procedimentos para a coleta dos dados.

\section{Apresentação da Temática e Delineamento da Pesquisa}

O presente estudo caracteriza-se por sua natureza descritivo-interpretativa. Segundo Van Dalen e Meyer (1971, p. 226): “[ . . . ] a pesquisa é descritiva quando seu objetivo consiste em chegar a conhecer as situações, costumes e atitudes predominantes, mediante a descrição exata das atividades, objetos, processos e pessoas". Conhecer como vive o idoso de classe média e propor uma linha de ação que permita uma maior integração e fortalecimento de seus vínculos familiares e comunitários foi o objetivo que nos levou a esta pesquisa. A população se constituiu de idosos residentes em Rio Grande (RS), 
do sexo masculino e feminino, entre 70 e 75 anos, pertencentes à classe média e vivendo fora de instituições. A amostra ficou constituída por dez idosos, cinco do sexo masculino e cinco do sexo feminino. A escolha dos sujeitos da pesquisa foi intencional e teve por objetivo garantir a existência das características especificadas como necessárias para a composição da amostra. Referindo-se à escolha intencional, Selltiz et al. (1974, p. 603) nos afirmam que:

[ . . ] as principais vantagens da amostragem não probabilística são a facilidade e a economia. É provável que muitas operações futuras de amostragem sejam realizadas de acordo com os princípios não probabilísticos, na medida em que os pesquisadores estejam convencidos de que tais processos de amostragem são razoavelmente satisfatórios.

Para a coleta dos dados, foi elaborada pela pesquisadora uma entrevista semi-estruturada com base no esboço proposto por Van Hoose e Worth (1985), a qual deriva do Esquema de Entrevista e Escala de Ajustamento Adulto Vaillant, de 1977. O roteiro segue a premissa dos mesmos autores que domínios específicos da vida adulta proporcionam uma base para análise da situação existencial do cliente. O primeiro bloco de questões, que trata do estado evolutivo, pretende classificar o entrevistado de acordo com a idade, sexo, moradia, nível educacional, profissional e econômico. O segundo bloco de perguntas, relativas ao estado psicológico, nos dá informa-ções acerca do autoconceito do cliente, como se vê e enfrenta a realidade. Inclui também questões relativas ao trabalho, considerando a importância da ocupação no ajustamento pessoal. O terceiro bloco da entrevista contém perguntas sobre relações humanas. $\mathrm{O}$ último bloco da entrevista indaga a respeito da saúde do entrevistado. As questões da entrevista, elaboradas de acordo com o exposto, fornecem dados que são indicadores da situação existencial do adulto velho de classe média e permitem traçar o perfil do idoso entrevistado, propondo ações com vistas à melhoria da qualidade de vi-da. Os idosos foram entrevistados individualmente, não houve preocupação com o tempo de duração da entrevista, respeitando-se as diferenças e o ritmo da cada um. Todas as entrevistas foram gravadas e transcritas para posterior análise e interpretação. 


\section{Análise e Interpretação dos Dados}

A interpretação dos dados colhidos foi feita observando a seqüência das questões que integraram cada bloco da entrevista. Visando complementar os dados colhidos, analisamos os depoimentos feitos pelos entrevistados no final do encontro.

\subsection{Estado Evolutivo}

No primeiro bloco de questões, foram levantados e discutidos dados referentes ao nível de instrução, moradia, renda e profissão. Em relação ao nível de instrução, todos tiveram acesso à educação formal. Acredita-se que o grau de instrução se constitui em fator importante no processo de integração dos indivíduos na sociedade, com repercussão considerável em sua ocupação, na formação de hábitos, costumes e valores. Os homens apresentaram maior escolaridade que as mulheres. As mulheres viveram numa época em que o acesso ao ensino básico e superior era mais um privilégio masculino. Em relação à moradia, como era previsto, já que se tratava de uma amostra de classe média, $80 \%$ dos pesquisados moram em casas ou apartamentos próprios. Morar em casa própria é o ideal para o idoso. Zimerman (2000, p. 36) diz que "[...] se a casa tem muita importância para a maioria das pessoas, para o velho, assume um papel ainda mais relevante, pois é dentro dela que ele vai passar a maior parte do tempo". No que se refere às profissões exercidas pelos entrevistados, são relacionadas com serviços sociais, burocráticos, atividades de produção, profisssões liberais e serviços de administração. Em relação aos recursos econômicos, houve algumas queixas sobre a defasagem salarial decorrente de aposentadorias e pensões.

\subsection{Estado Psicológico e Social}

O segundo bloco da entrevista refere-se ao autoconceito, às interações sociais, necessidades, família, amigos, trabalho e lazer. Em relação à forma como se vêem na sociedade atual, houve uma tendência para se colocarem como expectadores e não como membros atuantes e integrantes da mesma. Isso ficou registrado através de algumas afirmações tais como: "Não tenho mais nada a fazer", "A minha opinião não conta", "Só os mais jovens são considerados". Zimerman (2000) nos afirma que, com a idade avançada, a 
integração do senescente com a comunidade tende a decrescer significativamente. Quando foram questionados a respeito das necessidades que consideram próprias às pessoas de sua faixa etária, as respostas se concentraram nos itens a seguir: "carinho", "amor dos filhos", "amigos", "compreensão", "saúde" e "lazer". Todos os entrevistados consideram importante o convívio carinhoso com a família. Quanto aos amigos, significam para eles "compreensão, solidariedade, ter com quem falar, discutir dúvidas". O lazer foi bastante citado como necessário ao idoso nesta etapa do ciclo vital. Segundo Jordão Neto (1986), o lazer representa atividade ou prática extremamente importante para uma recuperação psicossomática, e para o desenvolvimento social e pessoal dos seres humanos, especialmente do idoso. Tal atividade liberta do isolamento e solidão, e gratifica algumas horas da existência. As respostas dadas sobre o autoconceito permitem inferir a respeito de como se vêem como pessoa, qual a imagem que fazem de si e em que nível se encontra seu grau de autoestima. Acham que a opinião do idoso não é levada em consideração. Expressões como as que seguem se repetem: "a minha opinião não conta", "nada posso fazer", "só posso observar e procurar me adaptar" são comuns entre os entrevistados. Há uma manifestação de negatividade em relação às possibilidades de influir nos destinos da família e da sociedade e uma preferência dominante por contatos familiares e com o grupo reduzido de amigos. Reforçando essa afirmação cita-se Canôas (1985, p. 38), “[ . . . ] a família a todo o momento assume proporções avantajadas para o idoso". Quanto ao trabalho, alguns idosos, principalmente do sexo masculino, declararam sentir após a aposentadoria um grande mal estar. "É como se passássemos a viver ociosamente, há um grande vazio", afirmou um senhor. A aposentadoria confere ao idoso um sentimento de perda cultural e desvalorização social. Enquanto valores dominantes na sociedade que permanecerem associados ao trabalho, serão importantes para os velhos.

\subsection{Relações Humanas}

No terceiro bloco, os entrevistados responderam perguntas sobre relações humanas e afirmaram que têm amigos e gostam de fazer novos relacionamentos. Sobre isso Canôas $(1985$, p. 49) nos diz: "[ . . . ] os amigos tornam-se até mais importantes do que os parentes. Na verdade, ter amigos significa compreensão, solidariedade, ter com quem falar discutir dúvidas". Apesar de ter amigos e manifestar satisfação em relação ao fato, grande parte 
dos entrevistados falou que sente solidão $(60 \%)$ e que procura fazer algo para minorar esse sentimento. A solidão é ligada ao sentimento de perda, por isso aparece com mais intensidade na velhice. Neri (2001, p. 122) diz que a "[...] perda de papéis, afastamento, limitações físicas e financeiras e morte de entes queridos podem ocasionar solidão na velhice". Para minorar o sentimento de solidão, sugere-se a participação em centros culturais comunitários, onde são desenvolvidas diversas atividades e onde poderão também iniciar movimentos pela garantia de seus direitos civis.

\subsection{Saúde}

No último bloco, os idosos pesquisados relataram os problemas mais freqüentes no que diz respeito à saúde física, tais como: cardiopatias, problemas de coluna, afecções reumáticas, catarata, fraqueza geral, pressão alta. Apesar de possuírem alguns problemas e, como conseqüência, alguma limitação, os idosos em geral ainda se consideram saudáveis e acham que a doença não consegue impedir suas atividades normais. Os idosos entrevistados gozam de atendimento médico adequado, têm condições para adquirir medicamentos e são cuidados e atendidos pelos familiares em seus problemas de saúde. Nos últimos tempos, a parcela mais informada da população tem uma preocupação com o tipo de alimentação que ingere. Há cuidado em escolher produtos que contenham vitaminas, proteínas e outros elementos necessários à saúde.

\subsection{Depoimentos}

Antes de concluir a entrevista, foi solicitado a cada um dos indivíduos um depoimento sobre o assunto que considerava mais relevante. Dois entrevistados, um do sexo masculino e outra do sexo feminino fizeram referência à necessidade de mais respeito no atendimento ao idoso, afirmando: "Não há compreensão e a sociedade não prestigia seus idosos". A predominância das mensagens foi dirigida à situação social atual. Preocupam-se com o futuro dos filhos e netos quanto à segurança e bem estar. Expressões como "É preciso que se volte a amar"; "Atualmente há muito egoísmo e personalismo"; "A verdade e a honra não valem mais nada", foram usadas para exprimir o sentimento de descrença para com a sociedade atual.

Como conclusão, apresenta-se sinteticamente a situação existencial do idoso de classe média constituinte da amostra, inferida pela análise e 
interpretação dos dados, usando os indicadores de saúde, lazer, nível econômico, produtividade, família e amigos.

\subsubsection{Saúde}

Os problemas mais freqüentes entre os idosos pesquisados, no que diz respeito à saúde física, são: cardiopatias, problemas de coluna, afecções reumáticas, catarata, fraqueza geral, pressão alta. Tais enfermidades afetam o idoso em suas necessidades de percepção visual, locomoção, diminuição na capacidade para participar de atividades sociais e de lazer.

\subsubsection{Lazer}

Os idosos de classe média ainda participam da vida social e de atividades de lazer. Consideram-se adaptados e têm amigos. Há uma restrição nestas atividades, motivada pela própria velhice, doenças ou vontade crescente de se dedicar mais a atividades dentro de casa, como ver televisão, ler jornais, revistas, atividades manuais e outras.

\subsubsection{Nível Econômico}

O nível econômico influi significativamente na satisfação de suas necessidades fisiológicas e de segurança pessoal. Há uma preocupação por parte dos entrevistados quanto à defasagem salarial. As perdas salariais dos aposentados de classe média afetam, além de certas necessidades materiais, o status, o prestígio, a auto-imagem e a auto-estima.

\subsubsection{Produtividade}

Embora apenas um pesquisado continue com suas atividades normais, os restantes realizam pequenas tarefas que ocupam seu tempo, são agradáveis e permitem manter relacionamentos com outras pessoas. Os idosos que realizam tarefas manifestam a alegria que isto lhes proporciona, emana deles certo dinamismo e satisfação por serem úteis.

\subsubsection{Família}

A família é de grande significado na vida do adulto-velho. O convívio dos idosos nesta faixa etária é quase que totalmente dedicado a filhos e netos. A assistência familiar ao idoso é de importância fundamental. 


\subsubsection{Amigos}

Atribuem valor ao fato de terem amigos. Gostam de conversar com pessoas de qualquer idade, mas preferem os relacionamentos mais antigos, alguns até datam da infância. Estes amigos são cada vez em número menor, pois as perdas por morte são comuns nesta idade.

Tendo por base os resultados da pesquisa, tentou-se elaborar uma proposta de aconselhamento psicopedagógico que auxilie o idoso em seu processo de enfrentamento da problemática vivida nessa etapa vital. Através de cursos ministrados para integrantes de grupos de convivência e seus familiares, pretendeu-se debater e refletir sobre assuntos relevantes para o idoso com vistas à melhoria de sua vida pessoal, familiar e social.

\section{Uma Proposta de Aconselhamento Psicopedagógico}

Em cada etapa da vida, as pessoas se defrontam com tarefas específicas, enfrentam crises e têm necessidades de se adaptarem a novos papéis. Essa proposta de aconselhamento teve por objetivo ajudar o idoso sujeito da pesquisa a tomar consciência da melhor maneira de lidar com a problemática existencial desvelada nesse trabalho, esclarecer a família e a comunidade sobre as necessidades e características próprias dessa etapa da vida, propor ações com vistas à formação de atitudes positivas em relação ao idoso que contribuam para a consecução de condições de vida mais satisfatórias. Na velhice, os períodos de crise assumem maiores proporções, porque, além das deficiências pessoais próprias da idade, que dificultam o desenvolvimento, é necessário considerar a manipulação negativa que o idoso sofre por parte das forças sociais atuantes. $\mathrm{O}$ aconselhamento pretende exatamente deixar claro e definido este espaço. Van Hoose e Worth (1985, p. 49), referindo-se à importância do ser humano ocupar seu lugar na sociedade, de acordo com a etapa vital em que se encontra nos dizem:

[... ] essa abordagem evolutiva de aconselhamento leva em conta o estágio do desenvolvimento da pessoa, assim como as exigências sociais e oferece uma estrutura no interior da qual a pessoa pode assumir maior responsabilidade por seu próprio crescimento futuro, pelo gozo da vida, pela produtividade e pela realização pessoal. 
Para que o processo de aconselhamento seja válido, é preciso abordar assuntos comuns à problemática do idoso. Os temas a seguir, como sentido do trabalho, relacionamento familiar e sexualidade, foram destacados e abordados nos cursos pela relevância que têm nessa etapa da vida.

\subsection{Situação Ocupacional}

A ausência de trabalho e a inatividade decorrentes da aposentadoria, não trazem alegria nem felicidade. Por isso, a flexibilidade da idade de aposentadoria é imprescindível se quiser permitir que se realize toda a potencialidade de trabalho do indivíduo idoso. Pensando no valor de uma atividade para a manutenção do sentimento de valor e utilidade do idoso, Welford (1981, p. 153) aconselha que se oportunize ao idoso a permanência em empregos de meio expediente ou a mudança no tipo de atividade para outra que exija menor esforço físico. Para ele, a manutenção de algumas atividades talvez " [... ] ajude a preservar capacidades ao estimularem o esforço e darem novas oportunidades para o exercício de aptidões". O aposentado pode também continuar a ser ativo em outras funções relacionadas com seus interesses. Beauvoir (1976) diz que é muito importante para as pessoas de idade buscar ocupações. Sugere o ingresso em associações, excursões, participações em debates e centros de idosos, como forma de evitar a solidão e a sensação de inutilidade. Se a maior parte da identidade de uma pessoa provém do trabalho, o investimento em outras atividades pode ajudá-la a enfrentar a aposentadoria.

\subsection{A Família e o Idoso}

Com o advento da doença ou de problemas econômicos as pessoas idosas são obrigadas a morar com a família. A exploração positiva dessa situação pode reverter em benefício para todos os membros se for bem compreendida a dinâmica do inter-relacionamento familiar e os seus efeitos para o autoconceito de todos. O sentimento de pertencer a um grupo social e de compartilhar suas aspirações influi no bem estar mental idoso. Novaes fala das dificuldades de relacionamento e dos conflitos familiares que podem surgir, pois o idoso encontra-se dependente, fraco e magoado pela perda de prestígio. No entanto, é necessário que haja atitudes de tolerância e modos positivos de ver o idoso. A referida autora diz que: "Acreditar nas potencialidades 
do idoso, abrir um espaço para sua criatividade, estimular suas iniciativas e apoiá-lo com carinho e afeto trará segurança e confiança, ingredientes essenciais à reestruturação de suas vidas" (1997, p. 55). Quando velhos e jovens convivem numa mesma moradia, há para ambos um enriquecimento. No momento em que se estabelece uma convivência baseada no afeto, respeito e compreensão, desaparecem as distinções baseadas em idade cronológica e os conflitos entre gerações.

\title{
4.3 Sexualidade
}

A pessoa idosa continua a existir como ser sexual e precisa, por isso, expressar sua sexualidade. O idoso que envelhece ao lado do cônjuge tem uma velhice mais feliz. Estreitam-se os laços de amizade e afeto, e passam a viver um para o outro. $\mathrm{O}$ velho sozinho no mundo é um ser isolado e sofrido. Os jovens geralmente se opõem a um novo casamento dos pais. Desconhecem as necessidades de companheirismo salutar que protegem contra o abandono, pois na amizade ou em possível amor, podem encontrar o melhor meio de canalizar para elevados ideais, sua vida sexual. Butler e Lewis (1985, p. 17) demonstram o valor do relacionamento de amor durante a velhice, através das palavras seguintes:

\begin{abstract}
A sexualidade, reação física e emocional ao estímulo sexual, está além do impulso e do ato sexual. Para muitas pessoas de mais idade, ela oferece a oportunidade não apenas de expressar paixão, mas afeto e lealdade. Fornece provas afirmativas de que se pode contar com o corpo e seu funcionamento. Permite que as pessoas se afirmem positivamente. Traz consigo a possibilidade de emoção e romance. Expressa a alegria de estar vivo.
\end{abstract}

\section{Considerações Finais}

A problemática evidenciada através da pesquisa está fundamentalmente ligada à necessidade de convívio com a família e amigos e à maneira desrespeitosa como se percebem vistos pela sociedade. Para que o idoso seja reconhecido e valorizado em nosso país, torna-se urgente uma radical mudança da mentalidade da família e da sociedade. É hora de reivindicar o justo reconhecimento pela contribuição pessoal e social que essas pessoas 
vêm dando à sociedade. Para finalizar, apresentam-se sugestões de ações dirigidas à comunidade em geral, órgãos educacionais, instituições sociais e à família do idoso:

a) valorizar o idoso pela experiência, cultura e sabedoria que pode ser aproveitada em benefício das novas gerações;

b) proporcionar a permanência do idoso no lar e na comunidade, onde tem oportunidade de receber afeto, carinho e compreensão;

c) permitir a participação do idoso na educação das crianças e jovens; atribuir tarefas ao idoso, no lar, para que se sinta como membro atuante e participante;

d) oferecer oportunidades para novos relacionamentos, incentivando-o a participar de encontros sociais, culturais, artísticos e atividades de lazer;

e) aproveitar a cultura e experiência do idoso nas escolas, convidando-o para fazer palestras, participar de debates, entrevistas e encontros;

f) propiciar conhecimentos à população por meio de cursos, encontros, campanhas e propagandas sobre o processo de envelhecimento, e o tratamento adequado que se deve oferecer ao idoso.

\title{
EXISTENTIAL SITUATION OF THE ELDERLY IN MIDDLE CLASS
}

\begin{abstract}
The article shows a reflection about the collected data in a search which analyzed the biopsychosocial aspects of the elderly in middle class. Analyzing the content of the interview's answers is possible to perceive how "taught elderly" live. We suggest actions in order to change the attitudes, the family and social values concerning old age.

Keywords: Elderly People. Social Class. Advisement. Existential Situation.
\end{abstract}

\section{REFERÊNCIAS}

BEAUVOIR, Simone de. A Velhice. Realidade incômoda. São Paulo: Difel, 1976. 
BUTLER, Robert N.; LEWIS, Myrna I. Sexo e Amor na Terceira Idade. 2. ed. São Paulo: Summus, 1985.

CANÔAS, Cilene Swain. A Condição Humana do Velho. São Paulo: Cortez, 1985.

GALACHE, Gabriel C.; ANDRÉ, Manoel. Brasil, Processo e Integração. São Paulo: Loyola, 1992.

VAN HOOSE, Willian H.; WORTH, Maureen Rousset. Aconselhamento de Adultos. Uma abordagem evolutiva. Rio de Janeiro: Zahar, 1985.

JORDÃO NETO, Antonio. A Segregação do Velho na Sociedade. São Paulo: Secretaria de Descentralização e Participação, Conselho Estadual do Idoso, 1986.

NERI, Anita Liberalesso. Palavras-chave em Gerontologia. Campinas: Alínea, 2001.

NOVAES, Maria Helena. Psicologia da Terceira Idade. Conquistas possíveis e rupturas necessárias. 2. ed. Rio de Janeiro: NAU, 1997.

POULANTZAS, Nicos. As Classes Sociais no Capitalismo de Hoje. 2. ed. Rio de Janeiro: Zahar, 1978.

SANTOS, Theotonio dos. Conceitos de Classes Sociais. Petrópolis, Rio de Janeiro: Vozes, 1983.

SELLTIZ, Claire et al. Métodos de Pesquisa nas Relações Sociais. São Paulo: EPU, 1974.

VAN DALEN, Deobold B.; MEYER, William J. Manual de técnica de la investigación educacional. Buenos Aires: Paidós, 1971.

WELFORD, Alan Traviss. Velhice. Capacidades. In: SEARS, Robert R.; FELDMAN, S. Shirley. As Sete Idades do Homem. Rio de Janeiro: Zahar, p. 148-155, 1981. 
ZIMERMAN, Guite I. Velhice: aspectos biopsicossociais. Porto Alegre: ARTMED, 2000. 